\title{
Staphylococcus aureus isolated from selected dairies of Algeria: Prevalence and susceptibility to antibiotics
}

\author{
Asmaa Manel Matallah르, Leila Bouayad ${ }^{1}$, Sofiane Boudjellaba ${ }^{2}$, Faiza Mebkhout ${ }^{1}$, Taha Mossadak Hamdi ${ }^{1}$ and \\ Nadjia Ramdani-Bouguessa ${ }^{3}$
}

1. Laboratory of Food Hygiene and Quality Insurance System (HASAQ), Higher National Veterinary School, Rue Issad Abbes, Oued Smar, Algiers 16000, Algeria; 2. Research Laboratory Management of Local Animal Resources (GRAAL), Higher National Veterinary School, Rue Issad Abbes, Oued Smar, Algiers 16000, Algeria; 3. Laboratory of Medical Biology, Mohamed Mahmoudi City, Number 209 Bis, Baraki, Algiers, Algeria.

Corresponding author: Asmaa Manel Matallah, e-mail: matallahasma@yahoo.fr

Co-authors: LB: leila_bouayad@hotmail.com, SB: boudjellaba.sofiane@gmail.com, FM: scamilia2000@yahoo.fr, TMH: moussahamdi@hotmail.com, NRB: nramdanidz@yahoo.fr.

Received: 19-09-2018, Accepted: 26-12-2018, Published online: 08-02-2019

doi: 10.14202/vetworld.2019.205-210 How to cite this article: Matallah AM, Bouayad L, Boudjellaba S, Mebkhout F, Hamdi TM, Ramdani-Bouguessa N (2019) Staphylococcus aureus isolated form selected dairies of Algeria: Prevalence and susceptibility to antibiotics, Veterinary World, 12(2): 205-210.

\begin{abstract}
Aim: The objectives of this study were to assess the prevalence of Staphylococcus aureus in raw milk in Algerian dairies, to study the effect of seasons on the contamination of milk and the susceptibility of isolated strains to antibiotics, and to estimate the risk on the health consumer.
\end{abstract}

Materials and Methods: The ISO method 6888-1 (1) was used for Staphylococcus screening. Antimicrobial susceptibility to the 11 most used antibiotics in veterinary medicine was assessed using the disk diffusion assay.

Results: The overall prevalence was 31.56\% (95/301); 34.84\% (85/244) from raw milk collectors cisterns (MCC), 22.73\% $(5 / 22)$ from mixing tank milk before pasteurization, and $14.29 \%(5 / 35)$ from pasteurized tank milk $(\mathrm{p}<0.05)$. A significant difference $(p<0.001)$ of contamination on MCC was observed between dairies without season influence ( $p \geq 0.05)$. It was observed that $49.47 \%$ of $S$. aureus isolates were resistant to penicillin, $5.26 \%$ to tetracycline, $4.21 \%$ to erythromycin, $3.15 \%$ to neomycin, $2.10 \%$ to cefoxitin, $2.10 \%$ to clindamycin, and $1.05 \%$ to ofloxacin. No resistance was observed for vancomycin, gentamicin, chloramphenicol, and trimethoprim-sulfamethoxazole.

Conclusion: A high prevalence of $S$. aureus from MCC was observed without significant effect of season. The pasteurization does not ensure the elimination of bacteria in all samples. Half of the isolates were resistant to penicillin. These findings emphasize the importance of $S$. aureus control in Algerian milk industry at different levels to improve public health.

Keywords: antibiotic susceptibility, pasteurized milk, raw milk, Staphylococcus aureus.

\section{Introduction}

Zoonoses are infectious diseases that can naturally be transmitted between animals and humans. The severity of these diseases in humans may vary according to the main origin of the infection [1]. Raw milk may contain pathogenic microorganisms; it may occasionally play a role in the transmission of these pathogenic bacteria to humans. Among the most isolated pathogenic bacteria in milk that cause disease, we can cite Salmonella, Brucella, Listeria, Escherichia coli, and Staphylococcus aureus [2]. Some strains of $S$. aureus are the causative agents of foodborne intoxication [3]; their pathogenicity effects are due to the thermostable enterotoxins [4]. Pasteurization eliminates $S$. aureus bacterium, however, once formed, the thermostable enterotoxins make them their biological

\footnotetext{
Copyright: Matallah, et al. Open Access. This article is distributed under the terms of the Creative Commons Attribution 4.0 International License (http://creativecommons.org/licenses/ by/4.0/), which permits unrestricted use, distribution, and reproduction in any medium, provided you give appropriate credit to the original author(s) and the source, provide a link to the Creative Commons license, and indicate if changes were made. The Creative Commons Public Domain Dedication waiver (http:// creativecommons.org/publicdomain/zero/1.0/) applies to the data made available in this article, unless otherwise stated.
}

activity $[5,6]$. Monitoring the resistance of bacteria of the animal origin allows collecting a set of data to characterize trends, to detect new events at the origin of an alert, to document the level of the resistance of different bacterial species, and, finally, to study the emergence of new serotypes with antibiotic resistance profiles.

The emergence of antibiotic-resistant bacteria has become a global public health concern affecting human and veterinary medicine [7]. In fact, the administration of antibiotics for the feeding of animals for curative purposes or as growth promoters may be a major factor in the selection of antimicrobial-resistant bacteria [8].

The objectives of this study were to assess the prevalence of $S$. aureus in raw milk in dairies, to study the effect of seasons on the contamination of milk and the susceptibility of isolated strains to antibiotics, and to estimate the risk on the health consumer.

\section{Materials and Methods}

\section{Ethical approval}

The raw milk was taken from collectors cisterns, which did not need contact with animals. The present 
study did not involve any invasive procedure, and hence, ethical approval is not required.

\section{Sampling}

The study was carried out during the period from March 2016 to March 2017 and was realized in three different dairies, two of them located in the Wilaya of Algiers ("A" and "B") and one in the Wilaya of Boumerdès "C." In total, 301 samples were collected at three processing steps: (i) At milk reception from different collectors, (ii) after mixing milks before pasteurization, and (iii) after pasteurization. The volumes collected were $5 \times 100 \mathrm{ml}$ of milk for each sample according to the Algerian interministerial decree of 2016 fixing the microbiological criteria for foodstuffs N39/2017.

- 244 samples of raw milk were from cisterns of different collectors (milk collectors cisterns [MCC]).

- 22 samples of raw milk were from the mixing tank of different milks before pasteurization (MTMBP).

- 35 samples were from milk tank after pasteurization (TMP).

The samples were collected during the four seasons of this year: 112 samples were collected during the spring, 60 in summer, 57 in fall, and 72 in winter. After aseptic sampling and identification, the samples are quickly refrigerated and transported into a cooler to the food hygiene Laboratory of the Higher National Veterinary School, where they were analyzed the same day.

\section{Bacteriological analysis}

The Baird-Parker agar supplemented with 5\% egg yolk and $0.5 \%$ potassium tellurite was used for bacteriological isolation according to the ISO 6888-1 method. The putative colonies were tested for catalase, coagulase rabbit plasma and the Pastorex Staph Plus assay (Bio-Rad, Marnes-la-Coquette, France) are considered as $S$. aureus strains, the isolates that responded positively to the three tests.

\section{Study of susceptibility to antibiotics}

The susceptibility of isolated strains was tested with 11 antibiotics belonging to the different classes ( $\beta$-lactamines, cyclin, aminoglycosides, macrolides, quinolones, glycopeptides, phenicoles, and sulfa) by the disk diffusion method on Mueller-Hinton agar (Conda-Pronadisa, Madrid, Spain), according to the standards $[9,10]$ recommended by the WHO. The antibiotic discs (BioRad, Marnes-la-Coquette, France) used are as follows: Penicillin (10 UI), cefoxitin $(30 \mu \mathrm{g})$, tetracycline $(30 \mu \mathrm{g})$, neomycin $(30 \mu \mathrm{g})$, gentamicin $(10 \mu \mathrm{g})$, erythromycin $(15 \mu \mathrm{g})$, clindamycin $(2 \mu \mathrm{g})$, ofloxacin $(5 \mu \mathrm{g})$, vancomycin $(30 \mu \mathrm{g})$, chloramphenicol $(30 \mu \mathrm{g})$, and trimethoprim + sulfamethoxazole $(1.25 / 23.73 \mu \mathrm{g})$.

\section{Statistical analysis}

The results were analyzed statistically using the SPSS software for Windows (version 20.0; SPSS Inc., Chicago, IL, USA). Descriptive statistics and the relationship between contamination samples and different types of samples were analyzed using Chisquare test. The effect of season and milk provenance and milk nature on contamination samples was analyzed using Chi-square analysis. The level of significance was determined at confidence levels of $\mathrm{p}<0.05$.

\section{Results}

From the 301 samples tested, 95 (31.56\%) were found positive for $S$. aureus, distributed as follows: $34.83 \%(85 / 244)$ of MCC samples, $22.73 \%(5 / 22)$ of MTMBP, and $14.29 \%(5 / 35)$ of TMP $(\mathrm{p}<0.05)$, respectively. The MCC samples collected from the three dairies $\mathrm{A}, \mathrm{B}$, and $\mathrm{C}$ had contamination rates of $14.29 \%(3 / 21)$, $26.47 \%$ (36/136), and 52.87\% (46/87), respectively (Table-1). The MTMBP showed the levels of contamination for the three dairies A, B, and C of $10 \%(1 / 10)$, $28.57 \%(2 / 7)$, and $40 \%(2 / 5)$, respectively. The TMP collected from the dairies A and B showed contamination rates of $18.18 \%(2 / 11)$ and $23.08 \%(3 / 13)$, respectively. No TMP contamination was recorded in dairy C.

The rates of the contamination of MCC samples recorded during the spring, summer, fall, and winter season were $38.94 \%$ (37/95), 40\% (20/50), 34.15\% $(14 / 41)$, and $24.13 \%$ (14/58), respectively ( $\mathrm{p} \geq 0.05)$. MTMBP contamination rates recorded during three seasons, spring, summer, and fall were $16.67 \%(1 / 6)$, $33.33 \%(1 / 3)$, and $42.86 \%(3 / 7)$, respectively. TMP samples showed contamination rates during the two seasons, spring and summer of $27.27 \%(3 / 11)$ and $28.57 \%(2 / 7)$, respectively. No contamination was recorded during the fall and winter. The MCC samples from dairy A showed no contamination during three seasons, spring, fall, and winter, but the rate of contamination recorded during the summer season was $75 \%(3 / 4)$. In the same dairy, no contamination was also recorded in MTMBP and TMP during the same three seasons, but the rates of contamination recorded during the summer were $50 \%(1 / 2)$ and $66.67 \%(2 / 3)$, respectively. The MCC from the dairy B showed the levels of the contamination of $36.21 \%(21 / 58)$, $20.83 \%(5 / 24), 20 \%(4 / 20)$, and $17.65 \%$ (6/34) during the spring, summer, fall, and winter seasons, respectively. A contamination rate of the MTMBP samples of $66.67 \%(2 / 3)$ was recorded only during the fall. TMP samples recorded a contamination rate of $60 \%(3 / 5)$ during spring, and no contamination was recorded in other seasons. In dairy $\mathrm{C}$, the levels of the contamination of MCC samples were $50 \%(16 / 32)$, $54.55 \%(12 / 22), 62.50 \%(10 / 16)$, and $47.06 \%(8 / 17)$ during spring, summer, fall, and winter, respectively. The levels of MTMBP contamination were $50 \%(1 / 2)$ and $100 \%(1 / 1)$ for spring and fall seasons, respectively. TMP did not present any contamination during the four seasons.

\section{Susceptibility of strains to antibiotics}

A total of $41.05 \%$ of tested strains were sensitive to all tested antibiotics; $47.36 \%$ (45/95) had monoresistance, including $3.15 \%(03 / 95)$ to erythromycin, 
$1.05 \%(01 / 95)$ to ofloxacin or tetracycline, and $42.10 \%$ (40/95) to penicillin. Double resistance was observed in $4.21 \%(04 / 95)$ of the isolates, two to neomycin and penicillin, one to cefoxitin and penicillin, and one to tetracycline and penicillin. Multiple antibiotic resistance was observed in $3.15 \%(03 / 95)$ of the isolates, among which one included resistance to cefoxitin, neomycin, and penicillin. The remaining two of isolates coming from the same collector sampled in two different seasons (summer and winter) were resistant to tetracycline, erythromycin, clindamycin, and penicillin. Intermediate susceptibility was observed in $7.36 \%(07 / 95)$ of the isolates: Trimethoprimsulfamethoxazole, clindamycin, neomycin, or ofloxacin. One of them showed intermediate susceptibility to two antibiotics (trimethoprim-sulfamethoxazole and ofloxacin) (Table-2). The overall resistance rates were $49.47 \%$ for penicillin, $5.26 \%$ for tetracycline, $4.21 \%$ for erythromycin, $3.15 \%$ for neomycin, $2.10 \%$ for cefoxitin, $2.10 \%$ for clindamycin, and $1.05 \%$ for ofloxacin. No resistance was observed for vancomycin, gentamicin, and chloramphenicol. The intermediate sensitivity was observed for the following antibiotics: $1.05 \%$ for clindamycin, $5.26 \%$ for trimethoprim + sulfamethoxazole, $1.05 \%$ for ofloxacin, and $1.05 \%$ for neomycin (Table-3).

\section{Discussion}

$S$. aureus is considered to be the most common mammary pathogen found in bovine mastitis in the whole world and is an obvious contributor to milk contamination [11]. In the present study, the MCC was the most contaminated milk type presenting rate contamination of $34.84 \%$. This rate was higher than that recorded in previous studies in Western of Algeria [12] and the central region of our country $[13,14]$ with rates of $26.25 \%, 18 \%$, and $29.81 \%$, respectively. It is higher than that of recorded in Iran (21\%) [15] and is also significantly higher than rates noted in India (6.00\%) [16] and in Brazil (7.03\%) [17]. This difference can be attributed to the fact that the most of these researchers carried out their samples on farms, while our study was interested in the milk of collectors who underwent several means of transport and manipulations before arriving at the dairy from where they were taken. The same rate is lower than that noted

Table-1: Contamination of milk (MCC, MTMBP, and TMP) by S. aureus according to dairies and season.

\begin{tabular}{|c|c|c|c|c|}
\hline Parameters & Total (n) & Positive (number of people) & Positive (\%) & p-value \\
\hline \multicolumn{5}{|l|}{ MCC } \\
\hline Dairy A & 21 & 3 & 14.29 & \multirow[t]{3}{*}{$<0.001$} \\
\hline Dairy B & 136 & 36 & 26.47 & \\
\hline Dairy C & 87 & 46 & 52.87 & \\
\hline \multicolumn{5}{|l|}{ МТМBP } \\
\hline Dairy A & 10 & 1 & 10 & \multirow[t]{3}{*}{ NS } \\
\hline Dairy B & 7 & 2 & 28.57 & \\
\hline Dairy C & 5 & 2 & 40 & \\
\hline \multicolumn{5}{|l|}{ TMP } \\
\hline Dairy A & 11 & 2 & 18.18 & \multirow[t]{3}{*}{ NS } \\
\hline Dairy B & 13 & 3 & 23.08 & \\
\hline Dairy C & 11 & 0 & 0 & \\
\hline \multicolumn{5}{|l|}{ MCC } \\
\hline Fall & 41 & 14 & 34.15 & \multirow[t]{4}{*}{ NS } \\
\hline Summer & 50 & 20 & 40.00 & \\
\hline Winter & 58 & 14 & 24.14 & \\
\hline Spring & 95 & 37 & 38.95 & \\
\hline \multicolumn{5}{|l|}{ MTMBP } \\
\hline Fall & 7 & 3 & 42.86 & \multirow[t]{4}{*}{ NS } \\
\hline Summer & 3 & 1 & 33.33 & \\
\hline Winter & 6 & 0 & 0.00 & \\
\hline Spring & 6 & 1 & 16.67 & \\
\hline \multicolumn{5}{|l|}{ TMP } \\
\hline Fall & 9 & 0 & 0.00 & \multirow[t]{5}{*}{ NS } \\
\hline Summer & 7 & 2 & 28.57 & \\
\hline Winter & 8 & 0 & 0.00 & \\
\hline Spring & 11 & 3 & 27.27 & \\
\hline Total & 301 & 95 & 31.56 & \\
\hline
\end{tabular}

**NS=Not significant $(\mathrm{p} \geq 0.05)$, S. aureus=Staphylococcus aureus, MCC=Milk collectors cisterns, MTMBP=Mixing tank of different milks before pasteurization

Table-2: Resistance profile of $S$. aureus isolates to antibiotics.

\begin{tabular}{lccccc}
\hline $\begin{array}{l}\text { Number of } \\
\text { stains }\end{array}$ & $\begin{array}{c}\text { Sensitive to all } \\
\text { ATB (\%) }\end{array}$ & $\begin{array}{c}\text { Single } \\
\text { resistance (\%) }\end{array}$ & $\begin{array}{c}\text { Double } \\
\text { resistance (\%) }\end{array}$ & $\begin{array}{c}\text { Multiple ( } \mathbf{3}) \\
\text { résistance (\%) }\end{array}$ & $\begin{array}{c}\text { Intermediate } \\
\text { sensitivity (\%) }\end{array}$ \\
\hline 95 & $39(41.05)$ & $45(47.36)$ & $4(4.21)$ & $3(3.15)$ & $7(7.36)$ \\
\hline
\end{tabular}

S. aureus=Staphylococcus aureus 
Table-3: Susceptibility of $S$. aureus isolates to tested antibiotics.

\begin{tabular}{lcccr}
\hline Antibiotics & Break points $(\mathbf{m m})$ & Sensible (\%) & Intermediate (\%) & Resistant (\%) \\
\hline TE & $14-1$ (\% $^{*}$ & $90(94.73)$ & 0 & $5(5.26)$ \\
E & $13-23^{*}$ & $91(95.78)$ & 0 & $4(4.21)$ \\
CM & $14-21^{*}$ & $92(96.84)$ & $1(1.05)$ & $2(2.10)$ \\
SXT & $10-16^{*}$ & $90(94.73)$ & $5(5.26)$ & 0 \\
OFX & $14-18^{*}$ & $93(97.89)$ & $1(1.05)$ & $1(1.05)$ \\
VA & $\geq 15^{* *}$ & $95(100)$ & 0 & 0 \\
GM & $12-15^{*}$ & $95(100)$ & $1(1.05)$ & $3(3.15)$ \\
N & $13-18^{*}$ & $91(95.78)$ & 0 & 0 \\
C & $12-18^{*}$ & $95(100)$ & 0 & $47(49.47)$ \\
P & $28-29 *$ & $48(50.52)$ & 0 & $2(2.10)$ \\
FOX & $21-22 *$ & $93(97.89)$ & 0 & 0 \\
\hline
\end{tabular}

$\mathrm{C}=$ Chloramphenicol, $\mathrm{CM}=$ Clindamycin, $\mathrm{E}=$ Erythromycin, $\mathrm{FOX}=$ Cefoxitin, $\mathrm{GM}=$ Gentamicin, $\mathrm{N}=$ Neomycin, OFX=Ofloxacin, $P=$ Penicillin, SXT=Trimethoprime+Sulfamethoxazole, TE=Tetracycline, VA=Vancomycin, *CLSI [9], ** CLSI [10], S. aureus $=$ Staphylococcus aureus

by Hamiroune et al. [18] (58.5\%) who evaluated the bacteriological quality of raw milk at various stages of the production chain on farms in Algeria and that of in Brazil (68\%) [19]. It is also lower than the rate found in Northern Morocco (40\%) [20]. Milk is normally sterile if the cow does not suffer from clinical or subclinical mastitis [21]. Contamination may come from the udder itself or the non-observance of hygiene rules during milking, such as a deficiency of hygiene in hands, teat, and storage tanks [22]. Insufficient cleaning of milking machines and the use of contaminated water during milking would result in the persistence of $S$. aureus in raw milk [23]. This milk represents a danger in the dairy industry, as the production of staph toxin resistant to the thermal pasteurization process is normally found at a temperature of $40-45^{\circ} \mathrm{C}$ [24], although Smith [25] detected the production of toxins at a temperature of $10-46^{\circ} \mathrm{C}$. It was observed in this study that the milk refused at the level of the dairies were delivered to the points of sale to be resold on their own or converted into curdled milk and butter made in artisanal way, knowing that many people prefer consumption of cow's milk in the raw state [23]. The counts of $S$. aureus above $10^{3}$ increase the likelihood of the production of boiling resistant staphylococcal toxins produced in households during the purchase of raw milk and the pasteurization process [26]. In our study, pasteurized milk showed a contamination rate of $14.29 \%(5 / 35)$. These results are lower than those observed by Freitas et al. [27] and De Oliveira et al. [19] with rates of $30.5 \%$ and $30 \%$, respectively. The persistence of $S$. aureus in pasteurized milk is probably related to the high initial charge of raw milk, the mixing of milk from several sources would promote cohabitation and the appearance of bacterial strains that are increasingly resistant to heat treatments. Pasteurized milk can also be predisposed to the probable production of the toxin cited by Chapaval et al. [28] because, in various situations, store owners turn off the chillers at night to save electricity, leaving the product exposed to the temperature variations [19]. In our study, the observed differences between dairies for the MCC would be due to poor hygiene conditions in dairy farms [29], or most probably due to the presence of subclinical mastitis that often passes unperceived, it may be due also to differences in practices in each dairy. This contamination would depend on the processing capacity of each dairy which could have a negative impact on compliance with the hygiene rules, this even in the presence of an informed control system. This situation results in a very long stay of milk in tanks before heat treatment. We also noted a higher frequency of collection for the dairy "C" (spread out over all the day) with several round trips, while in the other dairies, milk collection was held only early in the morning.

The results of our study also show that the contamination of MCC by S. aureus is not significantly different in terms of the seasons. However, it remains important and relatively equivalent during the three-quarters of the year (spring, summer, and fall) with a contamination rate of $38.94 \%, 40 \%$, and $34.16 \%$, respectively. Indeed, the North of Algeria is known for its high temperatures during this period favorable to the development of $S$. aureus. Effectively, episodes of temperature rise and close cohabitation of the animals in winter would explain the contamination noted even in winter (24.13\%). Chapaval et al. [28] showed that the production of staphylococcal enterotoxins in milk is noted when it is stored at a temperature of $37^{\circ} \mathrm{C}-42^{\circ} \mathrm{C}$ or when exposed to temperature fluctuations [28]. The study on UHT cow's milk deliberately contaminated with $S$. aureus showed significant development of $S$. aureus in milk incubated at $22^{\circ} \mathrm{C}$ and $32^{\circ} \mathrm{C}$ compared to that incubated at $12^{\circ} \mathrm{C}$ and $18^{\circ} \mathrm{C}$ [30].

During the summer period, dairy " $\mathrm{A}$ " was the most contaminated $(75 \%)$. This could be explained by the proliferation of $S$. aureus due to heat and their ability to form biofilm in collecting and storage tanks and their resistance to the insufficient cleaning. Knowing that there is only one collector that supplies this dairy and the milk collected in this dairy is used for the manufacturing of fermented milk, which can be contaminated because the growth of $S$. aureus at a low $\mathrm{pH}$ depends on the level of contamination initial, 
modalities of preparation, and the temperature of curdling [30].

The present study showed that $47.36 \%$ of isolates had resistance to a single antibiotic, $4.21 \%$ to two antibiotics, and $3.15 \%$ to several antibiotics. The result of this study was different from those obtained by Chaalal et al. [31] for single and multiple resistance $(5.3 \%$ and $83.9 \%)$. They are almost similar for double resistance $(6 \%)$. Two strains isolated in the same collector, isolated in two different seasons (summer and winter) had multiple resistance for the same antibiotics (tetracycline, erythromycin, clindamycin, and penicillin), this could be explained either by the persistence overtime of these resistant strains in a poorly washed material or in the udder after poorly treated mastitis. Our study showed that $49.47 \%$ of the strains studied were resistant to penicillin and $5.26 \%$ to tetracycline. Our results are lower than those observed in Algeria [12] (80.95\% for penicillin and $71.43 \%$ for tetracycline). This difference could be because of this last analyzed milk from subclinical mastitis. They are also lower than those noted by Thaker et al. [16] $(100 \%)$ for penicillin. Our results are higher than those obtained in Malaysia [32] for penicillin 23.3\% but similar for tetracycline $5.0 \%$ and chloramphenicol and gentamicin $00 \%$. They also reported the lowest rates of $15 \%$ to cefoxitin, $10 \%$ to clindamycin, and $8.3 \%$ to erythromycin. Liu et al. [33] observed resistances higher than ours for clindamycin $35.2 \%$, sulfamethoxazole-trimethoprim $20.4 \%$, erythromycin $46.3 \%$, and chloramphenicol $7.41 \%$. The high percentage of resistant to penicillin $S$. aureus isolates may be due to previous contact with these antibiotics, particularly in the treatment of mastitis in dairy farms [34]. According to some authors, resistance is exacerbated by the abusive and systematic use of intramammary injections, especially during the drying period [35]. In Algeria, beta-lactams including penicillin $\mathrm{G}$ are largely used in the treatment of mastitis without any susceptibility testing of the bacterial strain against these antimicrobials [12]. The presence of antibiotic resistance in raw milk has the effect of weakening the efficacy of the antibiotic in the treatment of $S$. aureus infections in the consumer. The dissemination of resistant bacteria between different hosts can occur by contamination of food, air, or water. When it reaches a new host, the bacterium can colonize or infect it. It can then disseminate its genes of resistance to other bacteria and also receive genes of resistance from other bacteria [36].

\section{Conclusion}

In this study, the MCC has a high rate of positive samples for $S$. aureus. This contamination provides information on the health status of dairy cows and the lack of hygiene in livestock farms.

The persistence of $S$. aureus in pasteurized milk should attract attention to palliate this problem which could quickly become a plague for public health. High temperatures in our country and episodes of temperature rise, as well as permanent stalling during the winter period, seem to have no significant influence on the development of $S$. aureus. More than half of the strains isolated from $S$. aureus had intermediate susceptibility or resistance to one or more antibiotics, this result would result from the abusive and inappropriate use of these antibiotics in dairy farms and could be a serious problem for human health.

\section{Authors' Contributions}

AMM designed and conducted the work. AMM and FM were responsible for sample collection and antibiogram analysis. AMM and LB contributed equally to isolate and identify $S$. aureus. LB and SB carried out the statistical analysis. The manuscript was drafted by AMM under the guidance of TMH and NRB. All authors read and approved the final manuscript.

\section{Acknowledgments}

The authors are thankful to the dairies (Battouche, Colaital, and LFB) to their collaboration and providing the facilities to carry out the research work. Furthermore, we would like to express our hearty appreciation, sincere thanks to Mohamed Matallah (former head of the Department of Centre Pierre Marie Curie of Algiers, Algeria) and Khaled Harhoura for great help, and encouragement through this study. The authors did not receive financial assistance from any source.

\section{Competing Interests}

The authors declare that they have no competing interests.

\section{Publisher's Note}

Veterinary World remains neutral with regard to jurisdictional claims in published institutional affiliation.

\section{References}

1. European Food Safety Authority. (2008) Report from the task force on zoonoses data collection including guidance for harmonized monitoring and reporting of antimicrobial resistance in commensal Escherichia coli and Enterococcus spp. from food animals. EFSA J., 141: 1-44.

2. Vahedi, M., Nasrolahei, M., Sharif, M. and Mirabi, A.M. (2013) Bactériological study of raw and unexpired pasteurized cow's milk collected at dairy farms and supermarkets in Sari city in 2011. J. Prev. Med. Hyg., 54(2): 120-123.

3. Pelisser, M.R., Klein, C.S., Ascoli, K.R., Zotti, T.R. and Arisil, A.C.M. (2009) Occurrence of Staphylococcus aureus and multiplex PCR detection of classic enterotoxin genes in cheese and meat products. Braz. J. Microbiol., 40(1): 145-148.

4. Sandel, M.K. and McKillip, J.L. (2004) Virulence and recovery of Staphylococcus aureus relevant to the food using improvement on traditional approaches. Food Control, 15(1): 5-10.

5. Becker, H., Bürk, C. and Märtlbauer, E. (2007) Staphylokokken-enterotoxine: Bildung, eigenschaften und nachweis. J. Verbr. Lebensm., 2(2): 171-189. 
6. Le Loir, Y., Baron, F. and Gautier, M. (2003) Staphylococcus aureus and food poisoning. Genet. Mol. Res., 2(1): 63-67.

7. French Food Safety Agency. (2006) Veterinary use of Antibiotics, Bacterial Resistance and Human Health Consequences. French Food Safety Agency, Markham.

8. Barber, D.A., Miller, G.Y. and McNamara, P.E. (2003) Models of antimicrobial resistance and foodborne illness: Examining assumptions and practical applications. J. Food Prot., 66(4): 700-709.

9. CLSI (2013) Performance Standards for Antimicrobial Susceptibility Testing Twenty-Third Informational Supplement. Clinical and Laboratory Standards Institute, Wayne, PA, USA.

10. CLSI. (2004) Document M31-S1: Performance Standards for Antimicrobial Disk and Dilution Susceptibility Tests for Bacteria Isolated from Animals; Informational Supplement. 24(17): 1-33.

11. André, M.C.D., Campos, M.R.H., Borges, L.J., Kipnis, A., Pimenta, F.C. and Serafini, A.B. (2008) Comparison of Staphylococcus aureus isolates from food handlers, raw bovine milk and minas frescal cheese by antibiogram and pulsed-field gel electrophoresis following Smal digestion. Food Control, 19: 200-207.

12. Belmamoun, A.R., Reguig, K.B., Bouazza, S. and Mustapha, M.D. (2016) Subclinical mastitis on the raw milk as a risk factor for the transmission of Staphylococcus aureus and coagulase-negative staphylococci, multidrug resistance in Sidi Bel Abbes, Algeria. Adv. Environ. Biol., 10(6): 1-11.

13. Titouche, Y., Hakem, A., Salmi, D., Yabrir, B., Chenouf, N., Chergui, A., Chenouf, A. and Houali, K. (2016) Assessment of microbiological quality of raw milk produced at TiziOuzou area (Algeria). Asian J. Anim. Vet. Adv., 11(12): 854-860.

14. Akkou, M., Antri, K., Bachtarzi, M.A., Bes, M., Tristan, A., Dauwalder, O., Kaidi, R., Meugnier, H., Tazir, M., Etienne, J., Laurent, F. and Ramdani-Bouguessa, N. (2016) Phenotypic and genotypic characterization of Staphylococcus aureus strains associated with bovine mastitis and nasal carriage of workers in contact to animals in Algeria. Pak. Vet. J., 36(2): 184-188.

15. Nazari, R., Godarzi, H., Baghi, F.R. and Moeinrad, M. (2014) Enterotoxin gene profiles among Staphylococcus aureus isolated from raw milk. Iran J. Vet. Res., 15(4): 409-412.

16. Thaker, H.C., Brahmbhatt, M.N. and Nayak, J.B. (2013) Isolation and identification of Staphylococcus aureus from milk and milk products and their drug resistance patterns in Anand, Gujarat. Vet. World, 6(1): 10-13.

17. Fagundes, H., Barchesi, L., Filho, A.N., Ferreira, L.M and Oliveira, C.A.F. (2010) The occurrence of Staphylococcus aureus in raw milk produced in dairy farms in the sãopaulo state, Brazil. Braz. J. Microbiol., 41(2): 376-380.

18. Hamiroune, M., Berber, A. and Boubekeur, S. (2016) Evaluation of the bacteriological quality of raw cow's milk at various stages of the milk production chain on farms in Algeria. Rev. Sci. Tech. Off. Int. Epiz., 35(3): 925-946.

19. De Oliveira, L.P., Barros, L.S.S., Silva, V.C. and Cirqueira, M.G. (2011) Study of Staphylococcus aureus in raw and pasteurized milk consumed in the Reconcavo area of the State of Bahia, Brazil. J. Food Process. Technol., 2(6): 1-5.

20. Bendahon, A., Lebbadi, M., Ennanei, L., Essadqui, F.Z. and Abdin, M. (2008) Characterization of Staphylococcus species isolated from raw milk and milk products (Iben and jben) in North Marocco. J. Infect. Dev. Ctries, 2(3): 218-225.
21. Holm, C. and Jespersen, L.A.A. (2004) Flow cytometric technique for quantification and differentiation of bacteria in bulk tank milk. J. Appl. Microbiol., 97(5): 935-941.

22. Bonfoh, B., Wasem, A., Traoré, A.N., Fané, A., Pillmann, H.S., Simbé, C.F., Alfaroukh, I.O., Nicolet, J., Farah, Z. and Zinsstag, J. (2003) Microbiological quality of cows' milk taken at different intervals from the udder to the selling point in Bamako (Mali). Food Control, 14(7): 495-500.

23. Hamiroune, M., Berber, A. and Boubekeur, S.(2014) Bacteriological quality of raw milk from local and improved markets in the regions of Jijel and Blida (Algeria) and impact on public health. Med. Vet., 158(2): 137-144.

24. Tortora, G.J., Funke, B.R. and Case, C.L. (2004) Microbiologia: An Introduction. $8^{\text {th }}$ ed. Pearson/Benjamin Cummings, San Francisco. p898.

25. Smith, J.L., Buchanan, R.L. and Palumbo, S.A. (1982) Effect of food environment on staphylococcal enterotoxin synthesis-a review. J. Food Prot., 46(6): 545-555.

26. Tebaldi, V.M.R., Oliveira, T.L., Boari, C.C.A. and Piccoli, R.H. (2008) Isolation of coliforms, staphylococci, and enterococci in raw milk from communitarian expansion refrigeration tanks: Identification, lipolytic and proteolytic action. Ciênc. Tecnol. Aliment. Camp., 28(3): 753-760.

27. Freitas, J.A., Oliveira, J.P. and Galinda, G.A.R. (2005) Evaluation of milk exposed to consumption in Northern Brazil. Rev. Inst. Adolfo Lutz, 64(2): 212-218.

28. Chapaval, L., Moon, D.H., Gomes, J.E., Duarte, F.R. and Tsai, S.M. (2010) Effect of temperature on production of staphylococcal enterotoxin in milk. Hig. Aliment, 24: 180-181.

29. Jamali, H., Paydar, M., Radmehr, B., Ismail, S. and Dadrasnia, A. (2015) Prevalence and antimicrobial resistance of Staphylococcus aureus isolated from raw milk and dairy products. Food Control, 54: 383-388.

30. LeMens, P., Lefrileux, Y., Tormo, H. and Vernozy-Round, C. (1999) Staphylococcus aureus's growth in the raw milk and goat cheeses. Renc. Rech. Rumin., 6: 299-302.

31. Chaalal, W., Aggad, H., Zidane, K., Saidi, N. and Kihal, M. (2016) Antimicrobial susceptibility profiling of Staphylococcus aureus isolates from milk. Br. Microbiol. Res. J., 13(3): 1-7.

32. Shamila-Syuhada, A.K., Rusul, G., Wan-Nadiah, W.A. and Chuah, L.O. (2016) Prevalence and antibiotics resistance of Staphylococcus aureus isolates isolated from raw milk obtained from small-scale dairy farms in Penang, Malaysia. Pak. Vet. J., 36(1): 98-102.

33. Liu, H., Li, S., Meng, L., Dong, L., Zhao, S., Lan, X., Wang, J. and Zheng, N. (2017) Prevalence, antimicrobial susceptibility, and molecular characterization of Staphylococcus aureus isolated from dairy herds in northern China. J. Dairy Sci., 100(11): 1-8.

34. Jamali, H., Radmehr, B. and Ismail, S. (2014) Prevalence and antibiotic resistance of Staphylococcus aureus isolated from bovine clinical mastitis. J. Dairy Sci., 97(4): 2226-2230

35. Kateete, D.P., Kabugo, U., Baluku, H., Nyakarahuka, L., Kyobe, S., Okee, M., Najjuka, C.F. and Joloba, M.L. (2013) Prevalence and antimicrobial susceptibility patterns of bacteria from milkmen and cows with clinical mastitis in and around Kampala, Uganda. PLoS One, 8(5): 1-12.

36. Swann, M.M., Baxter, K.L., Field, H.I., Howie, J.W., Lucas, I.A.M., Millar, E.L.M., Murdoch, J.C., Parsons, J.H. and White, E.G. (1969) Report of the Joint Committee on the Use of Antimicrobials in Animal Husbandry and Veterinary Medicine. CMND. 4190. HMSO, London. 